\title{
Association between Two Resistin Gene Polymorphisms and Metabolic Syndrome in Jilin, Northeast China: A Case-Control Study
}

\author{
Yingli Fu, ${ }^{1}$ Yaqin Yu, ${ }^{1}$ Yanhua Wu, ${ }^{2}$ Yueyue You, ${ }^{1}$ Yangyu Zhang, ${ }^{1}$ and Changgui Kou ${ }^{1}$ \\ ${ }^{1}$ Department of Epidemiology and Biostatistics, School of Public Health, Jilin University, Changchun, China \\ ${ }^{2}$ Division of Clinical Epidemiology, First Hospital of Jilin University, Changchun, China \\ Correspondence should be addressed to Changgui Kou; koucg@jlu.edu.cn
}

Received 26 July 2017; Revised 17 October 2017; Accepted 30 October 2017; Published 14 December 2017

Academic Editor: Dianjianyi Sun

Copyright @ 2017 Yingli Fu et al. This is an open access article distributed under the Creative Commons Attribution License, which permits unrestricted use, distribution, and reproduction in any medium, provided the original work is properly cited.

\begin{abstract}
Metabolic syndrome (MetS) is a significant health care problem worldwide and is characterized by increased fasting glucose and obesity. Resistin is a protein hormone produced both by adipocytes and immunocompetent cells, including those residing in adipose tissue, and is believed to modulate glucose tolerance and insulin action. This study examined the association of resistin gene polymorphisms, rs 1862513 and rs3745368, and related haplotypes with the development of metabolic syndrome in a Han Chinese population. This case-control study was performed on 3792 subjects, including 1771 MetS cases and 2021 healthy controls from the Jilin province of China. Metabolic syndrome was defined according to the criteria of the International Diabetes Federation (IDF). Logistic regression analysis was used to estimate the relationship between gene polymorphism and MetS. Our results showed that there were no significant associations between MetS and the genotype distributions in four kinds of inheritance models, allele frequencies, and related haplotypes of resistin gene polymorphisms rs1862513 and rs3745368 (all $p$ values $>0.05$ ). Based on our study findings, we concluded that mutations in resistin genes are not associated with the presence of MetS in a Han Chinese population from Jilin province in China.
\end{abstract}

\section{Introduction}

Metabolic syndrome (MetS) is defined by a combination of interconnected physiological, biochemical, clinical, and metabolic factors. It is characterized by a cluster of risk factors, including elevated blood pressure, increased fasting glucose, central obesity, and dyslipidemia (defined by increased triglycerides and reduced high-density lipoprotein cholesterol), as defined by the International Diabetes Federation (IDF) [1]

MetS confers an increased risk of diabetes mellitus, cardiovascular disease, stroke, myocardial infarction, and all-cause mortality. It is well recognized as a growing public health and clinical challenge worldwide, especially for lowand middle-income countries [1-3]. The prevalence of MetS around the world ranges from $10 \%$ to $84 \%$ [4]. The agestandardized prevalence of MetS among Chinese adults is $10.5 \%$, according to IDF criteria and data from the China Health and Nutrition Surveys (CHNS) in 2009 [5]. Due to the high health risks associated with MetS, the understanding of the precise pathogenesis of this metabolic disorder is the subject of intense investigation [6].

Resistin is a protein hormone produced both by adipocytes and immunocompetent cells, including those residing in adipose tissue [7]. Some evidence [8-10] suggests that resistin modulates glucose tolerance and insulin action, thereby playing a role in the pathogenesis of obesity and insulin resistance in humans. RETN, the gene coding for human resistin, is located on chromosome 19p13.3.6 [7]. The length of the RETN prepeptide in humans is 108 amino acids [8]. Taking into consideration that diabetes mellitus and obesity are major characteristics of MetS, the resistin gene was considered as a potential candidate gene for MetS in this study.

Up to $70 \%$ of the variation in circulating resistin levels can be explained by genetic factors, and several singlenucleotide polymorphisms in the RETN gene have been 
described so far $[11,12]$. One of the most frequently studied polymorphisms, RETN rs1862513, was reported to be associated with the regulation of RETN gene expression and serum resistin level [13-15]. Several studies have also associated the RETN rs1862513 polymorphism with obesity [16-18], insulin sensitivity [19], type 2 diabetes [15], and cerebrovascular disease [20]. As single-nucleotide polymorphisms (SNPs) in the $3^{\prime}$-untranslated region (3'UTR) of genes can affect gene expression and disease susceptibility [21], the rs3745368 SNP in the 3'UTR of the resistin gene might have an influence on resistin gene expression and thus influences the risk for the development of diabetes and hypertension [22].

The role of resistin in MetS remains controversial. Some studies showed that resistin levels correlated with obesity and diabetes $[23,24]$, while others failed to observe any correlation of resistin levels with metabolic markers [25, 26]. Meanwhile, several studies have shown that ethnicity plays an important role in this inconsistency [27, 28].

The primary goal of our study was to estimate the impact of RETN polymorphisms rs 1862513 and rs3745368 and their haplotypes on MetS and its individual components in a Northeastern Chinese population.

\section{Materials and Methods}

2.1. Study Population. A multistage stratified cluster sampling process was used to select the participants from nine areas of Jilin Province, Northeast China, in a communitybased survey conducted in 2012. There were four stages of sampling. In the first stage, the province was stratified by the nine regions corresponding to the administrative areas that are largely responsible for health care delivery. Secondly, four districts or counties were randomly selected from each of the nine regions using probability proportional to size (PPS) sampling. In the third stage, four or five communities were selected from both the rural and urban strata of each district or county using PPS. In the last stage, one resident was randomly selected from each household of each community. More detailed information on the sampling process can be found in previous publications [29, 30]. In this casecontrol study, frequency matching was used for the sampling. According to IDF criteria, 5702 Han Chinese individuals in the study were diagnosed with MetS. Among these individuals, there were 3792 participants who were without missing values on the necessary information, 1771 were randomly selected as cases from these 3792 participants, and 2021 subjects without MetS were recruited from the same source population as controls. We selected this subsample to optimize the genotyping costs and have sufficient power to detect statistically significant differences. The average age and the percent of male were matched within case and control groups.

In this study, MetS was diagnosed using the 2009 IDF criteria [31] that subjects must meet, that is, three or more of the following five criteria are required to be diagnosed with MetS: (a) elevated waist circumference $\geq 85 \mathrm{~cm}$ in males and $\geq 80 \mathrm{~cm}$ in females; (b) elevated triglycerides $\geq 150 \mathrm{mg} / \mathrm{dL}$ $(1.7 \mathrm{mmol} / \mathrm{L})$ or drug treatment for elevated triglycerides; (c) high-density lipoprotein cholesterol (HDL-C) $<40 \mathrm{mg} / \mathrm{dL}$ $(1.0 \mathrm{mmol} / \mathrm{L})$ in males and $<50 \mathrm{mg} / \mathrm{dL}(1.3 \mathrm{mmol} / \mathrm{L})$ in females or drug treatment for reduced HDL-C; (d) elevated blood pressure with systolic $\geq 130$ and/or diastolic $\geq 85 \mathrm{~mm} \mathrm{Hg}$ or antihypertensive drug treatment; and (e) elevated fasting glucose $\geq 100 \mathrm{mg} / \mathrm{dL}$ or drug treatment of elevated glucose. These criteria were generated by an IDF consensus group in 2004, with representatives from the organizations that had generated the previous definitions and members from all IDF regions. It allows for comparative long-term studies and is applicable to populations around the world [27, 32].

Demographic information (age, sex) and lifestyle factors (alcohol consumption and smoking status) were obtained by a self-report questionnaire. Body mass index (BMI), waist circumference, hip circumference, systolic blood pressure (SBP), diastolic blood pressure (DBP), and heart rate were measured by physical examination. Alcohol consumption was categorized into three levels according to self-reported frequency of drinking per week: normal drinker, often drinker, and never drinker. Subjects who drank over three times per week were categorized as often drinkers; those who drank more than one time but less than three times per week were categorized as normal drinkers, and those who drank less than one time per week during their lifetime were categorized as never drinkers. The smoking status was categorized into current smoker, former smoker, and never smoker according to the self-reported lifetime number of cigarettes and number of smoking days. Individuals who had smoked at least 100 cigarettes in their lifetime and were smoking during the time of the survey were defined as current smokers; individuals who had smoked at least 100 cigarettes but gave up smoking before the time of the survey were defined as former smokers, and individuals who had smoked fewer than 100 cigarettes during their lifetime were defined as never smoked. BMI was calculated as weight $(\mathrm{kg}) /$ height $\left(\mathrm{m}^{2}\right)$. Height and weight were measured in subjects standing straight and wearing light clothing without shoes. The waistline and hip circumferences were measured separately at the level of the individual's umbilicus and the maximum protrusion of the gluteal muscles, respectively. The SBP and DBP were recorded with an average of two measurements in a sitting position after a 10 -minute rest period with a mercury sphygmomanometer. Enzymatic methods were used to measure the total cholesterol (TC), triglycerides (TG), HDL-C, and low-density lipoprotein cholesterol (LDL-C) from blood lipids in a central laboratory. $5 \mathrm{~mL}$ blood samples were collected from all subjects in the morning after an overnight fast (at least 8 hours) and transported to the laboratory under refrigeration, and all four indexes mentioned above were assessed within 12 hours. Fasting blood glucose (FBG) was measured by a Bai Ankang fingertip blood glucose monitor (Bayer, Leverkusen, Germany) using fingertip blood samples. Both the demographic and clinical information were obtained at the same interview and test. More details on the methods have been reported in previous publications [33].

The ethics committee of the School of Public Health, Jilin University, approved our study and all subjects signed written informed consent before participating in this study.

2.2. DNA Extraction and Genotyping. According to previous studies [13, 15, 22], SNPs rs1862513 and rs3745368 were 
TABle 1: Demographic and biochemical parameters of study population.

\begin{tabular}{|c|c|c|c|c|}
\hline Parameters & Case $(n=1771)$ & Control $(n=2021)$ & $t / \chi^{2}$ & $p$ \\
\hline Age (year) & $49.49 \pm 0.23$ & $49.45 \pm 0.21$ & 0.115 & 0.907 \\
\hline \multicolumn{5}{|l|}{ Gender } \\
\hline Male & $884(49.9)$ & $1015(50.2)$ & 0.036 & 0.850 \\
\hline Female & $887(50.1)$ & $1006(49.8)$ & & \\
\hline BMI $\left(\mathrm{kg} / \mathrm{m}^{2}\right)$ & $27.21 \pm 0.07$ & $21.90 \pm 0.06$ & 54.533 & $<0.001^{*}$ \\
\hline $\mathrm{WC}(\mathrm{cm})$ & $91.28 \pm 0.19$ & $75.02 \pm 0.16$ & 65.743 & $<0.001^{*}$ \\
\hline $\mathrm{HC}(\mathrm{cm})$ & $99.73 \pm 0.15$ & $90.74 \pm 0.13$ & 45.067 & $<0.001^{*}$ \\
\hline HR (beat/min) & $79.06 \pm 0.26$ & $74.26 \pm 0.25$ & 13.230 & $<0.001^{*}$ \\
\hline $\mathrm{SBP}(\mathrm{mm} \mathrm{Hg})$ & $144.78 \pm 0.45$ & $120.22 \pm 0.35$ & 42.720 & $<0.001^{*}$ \\
\hline DBP (mm Hg) & $87.93 \pm 0.26$ & $74.61 \pm 0.21$ & 39.805 & $<0.001^{*}$ \\
\hline $\mathrm{TG}(\mathrm{mg} / \mathrm{dL})$ & $3.23 \pm 0.06$ & $1.09 \pm 0.01$ & 34.188 & $<0.001^{*}$ \\
\hline $\mathrm{TC}(\mathrm{mg} / \mathrm{dL})$ & $5.26 \pm 0.03$ & $4.72 \pm 0.02$ & 15.272 & $<0.001^{*}$ \\
\hline LDL-C (mg/dL) & $3.08 \pm 0.02$ & $2.84 \pm 0.02$ & 8.488 & $<0.001^{*}$ \\
\hline HDL-C (mg/dL) & $1.16 \pm 0.01$ & $1.62 \pm 0.01$ & -43.347 & $<0.001^{*}$ \\
\hline Fasting glucose $(\mathrm{mg} / \mathrm{dL})$ & $6.64 \pm 2.44$ & $4.85 \pm 0.98$ & 28.918 & $<0.001^{*}$ \\
\hline
\end{tabular}

Data are given as mean \pm SD or frequency (\% subjects); $p$ values were analyzed using Student's $t$-test or nonparametric test. ${ }^{*} A$ value of $p<0.05$ was considered statistically significant. BMI: body mass index; WC: waist circumference; HC: hip circumference; HR: heart rate; SBP: systolic blood pressure; DBP: diastolic blood pressure; TG: triglyceride; TC: total cholesterol; LDL-C: low-density lipoprotein cholesterol; HDL-C: high-density lipoprotein cholesterol.

selected by the Haploview program (https://www.ncbi.nlm .nih.gov/gene/) to identify the association between RETN gene polymorphism and MetS. The minor allele frequencies of these two SNPs were greater than 0.05 in Han Chinese population. A commercial DNA extraction kit (JiuNa Biotech Company, Hangzhou, China) was used to extract genomic DNA from peripheral blood lymphocyte samples ( $5 \mathrm{~mL}$ ). Assay design 3.1 software (Sequenom Inc., San Diego, CA) was used for designing the primers in polymerase chain reaction (PCR) for all the SNPs. SNP genotyping was determined using matrix-assisted laser desorption/ionization time of flight mass spectrometry (MALDI-TOF-MS). SNP genotyping reactions were performed in a 384-well Spectro-CHIP using a MassARRAY nanodispenser (Sequenom Inc.).

2.3. Statistical Analyses. The data analyses were conducted using STATA/IC (Version 14.2; Texas, USA) and the online SNP Stats (https://www.snpstats.net/snpstats/start.htm?) program. Demographic characteristics and MetS associated biochemical parameters were compared for subjects with and without MetS using the Pearson's chi-square $\left(\chi^{2}\right)$ and Student's $t$-test. The genotype distribution and allele frequency of the SNPs were compared between cases and controls using $\chi^{2}$ test. For each SNP, a Hardy-Weinberg disequilibrium (HWD) test was conducted in the control group. Logistic regression was used to calculate the odds ratios (OR) and 95\% confidence interval (95\% CI). SNP Stats was used to examine the potential associations between RETN gene haplotypes and risk of MetS. All tests were two sided, and statistical significance was considered as a $p$ value $<0.05$.

\section{Results}

3.1. Demographic Characteristics and Biochemical Features of Study Population. The average age of the case and control groups was $49.49 \pm 0.23$ and $49.45 \pm 0.21$ years, respectively. The percent of the male of the case and control groups was $49.9 \%$ and $50.2 \%$, respectively. The level of high-density lipoprotein cholesterol (HLD-C) was lower in the case group than that in the control group $(p<0.001)$, as expected. In contrast, the levels of other biochemical parameters were higher in the case group compared with the control group (Table 1).

3.2. Distributions of Genotype and Allele Frequencies in the Case and Control Groups. The results of the HWD test for the control group showed that the two RETN SNPs (rs1862513, 3745368) were in accordance with the HWD. As shown in Table 2, the frequencies of the genotypes and alleles of the two SNPs were not significantly different between the case and control groups, and there were no significant associations between both rs1862513 and rs3745368 gene polymorphisms and the risk of MetS after controlling for demographic and lifestyle factors in our results.

3.3. Distributions of Genotypes in the Case and Control Groups in Four Inheritance Models. Table 3 shows the adjusted odds ratios of genotypes in four inheritance models (codominant, dominant, recessive, and overdominant); results revealed no significant association between MetS risk and the two investigated single-nucleotide variants (rs1862513 and rs3745368) of the RETN gene $(p>0.05)$. 
TABLE 2: Distributions of genotypes/alleles and the risk estimates for the variant genotypes/alleles.

\begin{tabular}{|c|c|c|c|c|c|c|c|}
\hline SNP & Genotype & Cases (\%) & Controls (\%) & Crude OR (95\% CI) & $p$ & Adjusted OR* (95\% CI) & $p$ \\
\hline \multirow{5}{*}{ rs1862513 } & $\mathrm{CC}$ & $191(10.78)$ & $218(10.79)$ & 1 & 0.906 & 1 & 0.505 \\
\hline & GG & $800(45.17)$ & $918(45.42)$ & $0.99(0.80-1.23)$ & & $0.98(0.76-1.25)$ & \\
\hline & CG & $780(44.04)$ & 885 (43.79) & $1.01(0.81-1.25)$ & & $1.00(0.78-1.27)$ & \\
\hline & C-allele & $1162(32.81)$ & $1321(32.68)$ & 1 & 0.908 & 1 & 0.727 \\
\hline & G-allele & $2380(76.19)$ & $2721(67.32)$ & $0.99(0.90-1.10)$ & & $0.982(0.89-1.09)$ & \\
\hline \multirow{5}{*}{ rs37445368 } & GG & $1304(73.63)$ & $1471(72.79)$ & 1 & 0.541 & 1 & 0.536 \\
\hline & AA & $33(1.86)$ & $37(1.83)$ & $1.01(0.63-1.62)$ & & $0.98(0.58-1.66)$ & \\
\hline & GA & $434(24.51)$ & $513(25.38)$ & $0.95(0.82-1.11)$ & & $0.95(0.81-1.12)$ & \\
\hline & G-allele & $3042(85.88)$ & $3455(85.48)$ & 1 & 0.615 & 1 & 0.588 \\
\hline & A-allele & $500(14.12)$ & $587(14.52)$ & $0.97(0.85-1.10)$ & & $0.96(0.84-1.11)$ & \\
\hline
\end{tabular}

OR: odds ratio; CI: confidence interval. *Adjusted for age, sex, smoking status, and alcohol consumption.

TABLE 3: Genotype distribution by different inheritance models and odds ratio estimate.

\begin{tabular}{|c|c|c|c|c|c|c|}
\hline SNP & Genotype & Inheritance model & Case & Control & Adjusted OR (95\% CI)* & $p$ \\
\hline \multirow{9}{*}{ rs1862513 } & $\mathrm{C} / \mathrm{C}$ & Codominant & $191(10.8 \%)$ & $218(10.8 \%)$ & 1 & \multirow{3}{*}{0.96} \\
\hline & G/G & \multirow{4}{*}{ Dominant } & $800(45.2 \%)$ & $918(45.4 \%)$ & $0.98(0.79-1.21)$ & \\
\hline & $\mathrm{G} / \mathrm{C}$ & & $780(44 \%)$ & $885(43.8 \%)$ & $0.99(0.80-1.23)$ & \\
\hline & $\mathrm{C} / \mathrm{C}$ & & $191(10.8 \%)$ & $218(10.8 \%)$ & 1 & \multirow{2}{*}{0.88} \\
\hline & $\mathrm{G} / \mathrm{G}-\mathrm{C} / \mathrm{G}$ & & $1580(89.2 \%)$ & $1803(89.2 \%)$ & $0.98(0.80-1.21)$ & \\
\hline & $\mathrm{C} / \mathrm{C}-\mathrm{G} / \mathrm{G}$ & \multirow[t]{2}{*}{ Recessive } & $991(56 \%)$ & $1136(56.2 \%)$ & 1 & \multirow{2}{*}{0.86} \\
\hline & $\mathrm{G} / \mathrm{C}$ & & $780(44 \%)$ & $885(43.8 \%)$ & $1.01(0.89-1.15)$ & \\
\hline & $\mathrm{C} / \mathrm{C}-\mathrm{G} / \mathrm{C}$ & \multirow[t]{2}{*}{ Overdominant } & $971(54.8 \%)$ & $1103(54.6 \%)$ & 1 & \multirow{2}{*}{0.78} \\
\hline & G/G & & $800(45.2 \%)$ & $918(45.4 \%)$ & $0.98(0.86-1.12)$ & \\
\hline \multirow{9}{*}{ rs3745368 } & $\mathrm{G} / \mathrm{G}$ & Codominant & $1304(73.6 \%)$ & $1471(72.8 \%)$ & 1 & \multirow{3}{*}{0.84} \\
\hline & $\mathrm{A} / \mathrm{A}$ & & $33(1.9 \%)$ & $37(1.8 \%)$ & $0.97(0.60-1.57)$ & \\
\hline & $\mathrm{A} / \mathrm{G}$ & & $434(24.5 \%)$ & $513(25.4 \%)$ & $0.96(0.82-1.11)$ & \\
\hline & $\mathrm{G} / \mathrm{G}$ & Dominant & $1304(73.6 \%)$ & $1471(72.8 \%)$ & 1 & \multirow{2}{*}{0.56} \\
\hline & A/A-A/G & & 467 (26.4\%) & $550(27.2 \%)$ & $0.96(0.83-1.11)$ & \\
\hline & G/G-A/A & Recessive & 1337 (75.5\%) & $1508(74.6 \%)$ & 1 & \multirow{2}{*}{0.56} \\
\hline & $\mathrm{A} / \mathrm{G}$ & & $434(24.5 \%)$ & $513(25.4 \%)$ & $0.96(0.83-1.11)$ & \\
\hline & G/G-A/G & Overdominant & $1738(98.1 \%)$ & $1984(98.2 \%)$ & 1 & \multirow{2}{*}{0.95} \\
\hline & $\mathrm{A} / \mathrm{A}$ & & $33(1.9 \%)$ & $37(1.8 \%)$ & $0.98(0.61-1.59)$ & \\
\hline
\end{tabular}

OR: odds ratio; CI: confidence interval. *Adjusted for age, sex, smoking status, and alcohol status.

3.4. Association between Haplotypes and the Risk of MetS. Haplotype distributions were also performed and there was no significant difference between subjects with and without MetS (all $p>0.05)$ (Table 4).

\section{Discussion}

This case-control study was performed on 3792 subjects, including 1771 MetS cases and 2021 healthy controls, to explore the association between two resistin gene (rs1862513 and rs3745368) polymorphisms and MetS among Han Chinese population of Jilin, Northeast China. The major findings of this study were that there was no significant association between MetS and the genotype distributions in four types of inheritance models, allele frequencies, and related haplotypes of resistin gene rs1862513 and rs3745368 polymorphisms.

For rs1862513 gene polymorphism, the results in our study were consistent with previous reports in Thais [34] and in nondiabetic Caucasians [35] that resistin 5' variant rs1862513 probably do not influence susceptibility to MetS or any other metabolic feature including glucose, lipids, waist circumference, and blood pressure. But the results are still debatable. Some studies found that the GG genotype, or Gallele, of rs1862513 was correlated with increased prevalence of MetS [36-38]. And a study conducted by Boumaiza and his colleagues in Tunisian volunteers showed that the rs1862513 polymorphism was associated with risk of MetS components, such as obesity, higher waist circumference, higher BMI, and increased TC and LDL-C levels [7]. 
TABle 4: Associations between RETN haplotypes and risk of MetS.

\begin{tabular}{lcccccc}
\hline rs1862513 & rs3745368 & Total & $\begin{array}{c}\text { Frequency } \\
\text { Case }\end{array}$ & Control & Adjusted OR (95\%) & $p$ \\
\hline G & G & 0.6400 & 0.6395 & 0.6404 & 1 & \\
C & G & 0.2167 & 0.2193 & 0.2144 & $1.03(0.92-1.16)$ & 0.60 \\
C & A & 0.1107 & 0.1088 & 0.1124 & $0.97(0.84-1.13)$ & 0.73 \\
G & A & 0.0326 & 0.0324 & 0.0328 & $0.96(0.72-1.30)$ & 0.81 \\
\hline
\end{tabular}

Regarding the associations between the rs3745368 polymorphism and MetS, early studies reported varying results $[7,39-41]$. The presence of the G/A genotype was more frequent in the MetS group in Spanish subjects [39], and the presence of the A-allele was associated with metabolic markers in Mexican subjects [41]. By contrast, the polymorphism of rs3745368 was not associated with MetS risk in Tunisian [7] as well as Polish women [40], and these results were confirmed by our study.

One explanation of the discrepancy could be that the distribution of the polymorphism of interest appears to be quite different in distinct ethnic populations, and these genetic differences may contribute to varying prevalence rates of MetS among ethnic groups. Furthermore, the criteria for MetS' diagnosis could be a probable reason for the discrepancy. In our study, we used IDF criteria to diagnose MetS, but some other studies defined MetS according to the National Cholesterol Education Program Adult Treatment Panel III (NECPATPIII) [37] criteria. Compared with other criteria, the IDF definition requires obesity, but not necessarily insulin resistance. Also, different populations, ethnicities, and nationalities have a different distribution of norms for body weight and waist circumference, which could influence the results as well. Additionally, lifestyle, such as physical activity, sedentary lifestyle, and dietary habits, probably is an important factor that contributes to inconsistent results, as this factor affects the development of MetS [42, 43]. For example, among the Northeast Chinese people, most food preparations contain excessive salt, and this may be a risk factor for some MetS components, such as hypertension [44, 45]. Sedentary lifestyle, levels of work, and physical activity may also influence the development of MetS through BMI as a mediator [43].

This study presents novel data and findings that may have important implications for assessing MetS risk in the Han Chinese population of Northeast China. However, this study also has some limitations. First of all, MetS is the result of several combined factors; yet in this study, we only analyzed the correlation between RETN polymorphisms and MetS, thereby ignoring environmental factors and gene-environment interactions, which should be examined further. In addition, only two RETN polymorphisms were screened in this study, and further studies may be required to explore more thoroughly the possible role of resistin in the development of MetS. Furthermore, genotyping errors may introduce exposure identification bias, although genetic case-control studies suffer less with classification biases than classic epidemiologic studies [46]. Genotyping errors are common due to the presence of unknown SNPs in the neighboring nucleotides of a target SNP. Each method chosen can undergo misidentification of the SNP and error in the genotyping that obviously create a bias for analysis [47]. In our study, we did not evaluate the scale of genotyping errors. In summary, the search for potential gene candidates that may influence the development of MetS requires further investigation.

\section{Conflicts of Interest}

None of the authors have any potential conflicts of interest associated with this research.

\section{Acknowledgments}

This work was supported by the Scientific Research Foundation of the Health Bureau of Jilin Province, China (Grant no. 2011Z116). The authors are grateful to the Jilin Province Health Department, Chinese Jilin Provincial Centre for Disease Control and Prevention for supporting their project.

\section{References}

[1] J. Kaur, "A comprehensive review on metabolic syndrome," Cardiology Research and Practice, vol. 2014, Article ID 943162, 21 pages, 2014.

[2] D. Gu, K. Reynolds, X. Wu et al., "Prevalence of the metabolic syndrome and overweight among adults in China," The Lancet, vol. 365, no. 9468, pp. 1398-1405, 2005.

[3] R. Gupta, P. C. Deedwania, A. Gupta, S. Rastogi, R. B. Panwar, and K. Kothari, "Prevalence of metabolic syndrome in an Indian urban population," International Journal of Cardiology, vol. 97, no. 2, pp. 257-261, 2004.

[4] G. D. Kolovou, K. K. Anagnostopoulou, K. D. Salpea, and D. P. Mikhailidis, "The prevalence of metabolic syndrome in various populations," The American Journal of the Medical Sciences, vol. 333, no. 6, pp. 362-371, 2007.

[5] B. Xi, D. He, Y. Hu, and D. Zhou, "Prevalence of metabolic syndrome and its influencing factors among the Chinese adults: the China Health and Nutrition Survey in 2009," Preventive Medicine, vol. 57, no. 6, pp. 867-871, 2013.

[6] Y. Wu, S. Yu, S. Wang et al., "Zinc finger protein 259 (ZNF259) polymorphisms are associated with the risk of metabolic syndrome in a Han Chinese population," Clinical Laboratory, vol. 61, 2015.

[7] I. Boumaiza, A. Omezzine, J. Rejeb et al., “Association between four resistin polymorphisms, obesity, and metabolic syndrome parameters in Tunisian volunteers," Genetic Testing and Molecular Biomarkers, vol. 16, no. 12, pp. 1356-1362, 2012. 
[8] H. Wang, D. Y. Chen, J. Cao, Z. Y. He, B. P. Zhu, and M. Long, "High serum resistin level may be an indicator of the severity of coronary disease in acute coronary syndrome," Chinese Medical Sciences Journal, vol. 24, no. 3, pp. 161-166, 2009.

[9] S. Chu, W. Ding, K. Li, Y. Pang, and C. Tang, "Plasma resistin associated with myocardium injury in patients with acute coronary syndrome," Circulation Journal, vol. 72, no. 8, pp. 1249-1253, 2008.

[10] W. L. Hu, S. B. Qiao, Q. Hou, and J. S. Yuan, "Plasma resistin is increased in patients with unstable angina," Chinese Medical Journal, vol. 120, no. 10, pp. 871-875, 2007.

[11] H. Cao and R. A. Hegele, "Single nucleotide polymorphisms of the resistin (RSTN) gene," Journal of Human Genetics, vol. 46, no. 9, pp. 553-555, 2001.

[12] J. C. Engert, M. C. Vohl, S. M. Williams et al., " 5 ' flanking variants of resistin are associated with obesity," Diabetes, vol. 51, no. 5, pp. 1629-1634, 2002.

[13] Y. M. Cho, B. S. Youn, S. S. Chung et al., "Common genetic polymorphisms in the promoter of resistin gene are major determinants of plasma resistin concentrations in humans," Diabetologia, vol. 47, no. 3, pp. 559-565, 2004.

[14] K. Azuma, S. Oguchi, Y. Matsubara et al., "Novel resistin promoter polymorphisms: association with serum resistin level in Japanese obese individuals," Hormone and Metabolic Research, vol. 36, no. 8, pp. 564-570, 2004.

[15] H. Osawa, K. Yamada, H. Onuma et al., "The G/G genotype of a resistin single-nucleotide polymorphism at -420 increases type 2 diabetes mellitus susceptibility by inducing promoter activity through specific binding of Sp1/3," American Journal of Human Genetics, vol. 75, no. 4, pp. 678-686, 2004.

[16] V. S. Mattevi, V. M. Zembrzuski, and M. H. Hutz, "A resistin gene polymorphism is associated with body mass index in women," Human Genetics, vol. 115, no. 3, pp. 208-212, 2004.

[17] N. Xita, I. Georgiou, A. Tsatsoulis, A. Kourtis, A. Kukuvitis, and D. Panidis, "A polymorphism in the resistin gene promoter is associated with body mass index in women with polycystic ovary syndrome," Fertility and Sterility, vol. 82, no. 5, pp. 1466-1467, 2004.

[18] L. Bouchard, S. J. Weisnagel, J. C. Engert et al., "Human resistin gene polymorphism is associated with visceral obesity and fasting and oral glucose stimulated C-peptide in the Québec family study," Journal of Endocrinological Investigation, vol. 27, no. 11, pp. 1003-1009, 2004.

[19] H. Wang, W. S. Chu, C. Hemphill, and S. C. Elbein, "Human resistin gene: molecular scanning and evaluation of association with insulin sensitivity and type 2 diabetes in Caucasians," The Journal of Clinical Endocrinology \& Metabolism, vol. 87, no. 6, pp. 2520-2524, 2002.

[20] A. Kunnari, O. Ukkola, and Y. A. Kesaniemi, "Resistin polymorphisms are associated with cerebrovascular disease in Finnish type 2 diabetic patients," Diabetic Medicine, vol. 22, no. 5, pp. 583-589, 2005.

[21] R. Di Paola, L. Frittitta, G. Miscio et al., “A variation in 3' UTR of $h P T P 1 B$ increases specific gene expression and associates with insulin resistance," American Journal of Human Genetics, vol. 70, no. 3, pp. 806-812, 2002.

[22] M.-S. Tan, S.-Y. Chang, D.-M. Chang, J. C.-R. Tsai, and Y.-J. Lee, “Association of resistin gene $3^{\prime}$-untranslated region $+62 \mathrm{G} \rightarrow$ a polymorphism with type 2 diabetes and hypertension in a Chinese population," The Journal of Clinical Endocrinology \& Metabolism, vol. 88, no. 3, pp. 1258-1263, 2003.
[23] C. M. Steppan, S. T. Bailey, S. Bhat et al., "The hormone resistin links obesity to diabetes," Nature, vol. 409, no. 6818, pp. 307-312, 2001.

[24] P. G. McTernan, C. M. Kusminski, and S. Kumar, "Resistin," Current Opinion in Lipidology, vol. 17, no. 2, pp. 170-175, 2006.

[25] N. Iqbal, P. Seshadri, L. Stern et al., "Serum resistin is not associated with obesity or insulin resistance in humans," European Review for Medical and Pharmacological Sciences, vol. 9, no. 3, pp. 161-165, 2005.

[26] M. P. Reilly, M. Lehrke, M. L. Wolfe, A. Rohatgi, M. A. Lazar, and D. J. Rader, "Resistin is an inflammatory marker of atherosclerosis in humans," Circulation, vol. 111, no. 7, pp. 932-939, 2005.

[27] K. G. M. Alberti, P. Zimmet, and J. Shaw, "The metabolic syndrome-a new worldwide definition," The Lancet, vol. 366, no. 9491, pp. 1059-1062, 2005.

[28] R. B. Ervin, "Prevalence of metabolic syndrome among adults 20 years of age and over, by sex, age, race and ethnicity, and body mass index: United states, 2003-2006," National Health Statistics Reports, vol. 13, pp. 1-7, 2009.

[29] S. Wang, C. Kou, Y. Liu et al., "Rural-urban differences in the prevalence of chronic disease in Northeast China," Asia Pacific Journal of Public Health, vol. 27, no. 4, pp. 394-406, 2015.

[30] S. Wang, C. D'arcy, Y. Yu et al., "Prevalence and patterns of multimorbidity in Northeastern China: a cross-sectional study," Public Health, vol. 129, no. 11, pp. 1539-1546, 2015.

[31] K. G. Alberti, R. H. Eckel, S. M. Grundy et al., "Harmonizing the metabolic syndrome: a joint interim statement of the International Diabetes Federation Task Force on Epidemiology and Prevention; National Heart, Lung, and Blood Institute; American Heart Association; World Heart Federation; International Atherosclerosis Society; and International Association for the Study of Obesity," Circulation, vol. 120, no. 16, pp. 1640-1645, 2009.

[32] P. Zimmet, D. Magliano, Y. Matsuzawa, G. Alberti, and J. Shaw, "The metabolic syndrome: a global public health problem and a new definition," Journal of Atherosclerosis and Thrombosis, vol. 12, no. 6, pp. 295-300, 2005.

[33] Y. Wu, Y. Yu, T. Zhao et al., "Interactions of environmental factors and APOA1-APOC3-APOA4-APOA5 gene cluster gene polymorphisms with metabolic syndrome," PLoS One, vol. 11, no. 1, article e0147946, 2016.

[34] K. Suriyaprom, R. Tungtrongchitr, and P. Namjuntra, “Associations of resistin levels with resistin gene polymorphism and metabolic syndrome in Thais," Journal of Medical Biochemistry, vol. 34, no. 2, pp. 170-178, 2015.

[35] A. N. Qasim, T. S. Metkus, M. Tadesse et al., "Resistin gene variation is associated with systemic inflammation but not plasma adipokine levels, metabolic syndrome or coronary atherosclerosis in nondiabetic Caucasians," Clinical Endocrinology, vol. 70, no. 5, pp. 698-705, 2009.

[36] G. D. Norata, M. Ongari, K. Garlaschelli et al., "Effect of the $-420 \mathrm{C} / \mathrm{G}$ variant of the resistin gene promoter on metabolic syndrome, obesity, myocardial infarction and kidney dysfunction," Journal of Internal Medicine, vol. 262, no. 1, pp. 104$112,2007$.

[37] S. Kumar, V. Gupta, N. Srivastava et al., "Resistin 420C/G gene polymorphism on circulating resistin, metabolic risk factors 
and insulin resistance in adult women," Immunology Letters, vol. 162, no. 2, pp. 287-291, 2014.

[38] Y. Miyamoto, H. Morisaki, Y. Kokubo et al., "Resistin gene variations are associated with the metabolic syndrome in Japanese men," Obesity Research \& Clinical Practice, vol. 3, no. 2, pp. 65-74, 2009.

[39] N. Arraiz, C. Escalona, C. Prieto et al., “ 3 'UTR +62 G $>$ a polymorphism of the retn gene coding resistin and its association with metabolic syndrome components," Medicina Clínica, vol. 141, no. 8, pp. 325-331, 2013.

[40] W. Bik, J. Ostrowski, A. Baranowska-Bik et al., "Adipokines and genetic factors in overweight or obese but metabolically healthy Polish women," Neuro Endocrinology Letters, vol. 31, no. 4, pp. 497-506, 2010.

[41] E. Chavarria-Avila, S. L. Ruiz Quezada, M. O. GuzmanOrnelas et al., "Association of resistin gene $3^{\prime} U T R+62 G>a$ polymorphism with insulin resistance, adiposity and the adiponectin-resistin index in Mexican population," Nutricion Hospitalaria, vol. 28, no. 6, pp. 1867-1876, 2013.

[42] S. Bertrais, J. P. Beyeme-Ondoua, S. Czernichow, P. Galan, S. Hercberg, and J. M. Oppert, "Sedentary behaviors, physical activity, and metabolic syndrome in middle-aged French subjects," Obesity Research, vol. 13, no. 5, pp. 936-944, 2005.

[43] A. Wagner, J. Dallongeville, B. Haas et al., "Sedentary behaviour, physical activity and dietary patterns are independently associated with the metabolic syndrome," Diabetes \& Metabolism, vol. 38, no. 5, pp. 428-435, 2012.

[44] R. Baudrand, C. Campino, C. A. Carvajal et al., "High sodium intake is associated with increased glucocorticoid production, insulin resistance and metabolic syndrome," Clinical Endocrinology, vol. 80, no. 5, pp. 677-684, 2014.

[45] M. Y. Rhee, J. H. Kim, Y. S. Kim et al., "High sodium intake in women with metabolic syndrome," Korean Circulation Journal, vol. 44, no. 1, pp. 30-36, 2014.

[46] F. Pompanon, A. Bonin, E. Bellemain, and P. Taberlet, "Genotyping errors: causes, consequences and solutions," Nature Reviews Genetics, vol. 6, no. 11, pp. 847-846, 2005.

[47] A. G. Pacheco and M. O. Moraes, "Genetic polymorphisms of infectious diseases in case-control studies," Disease Markers, vol. 27, no. 3-4, pp. 173-186, 2009. 


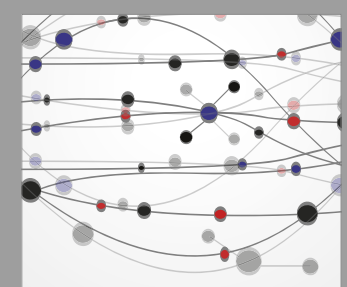

The Scientific World Journal
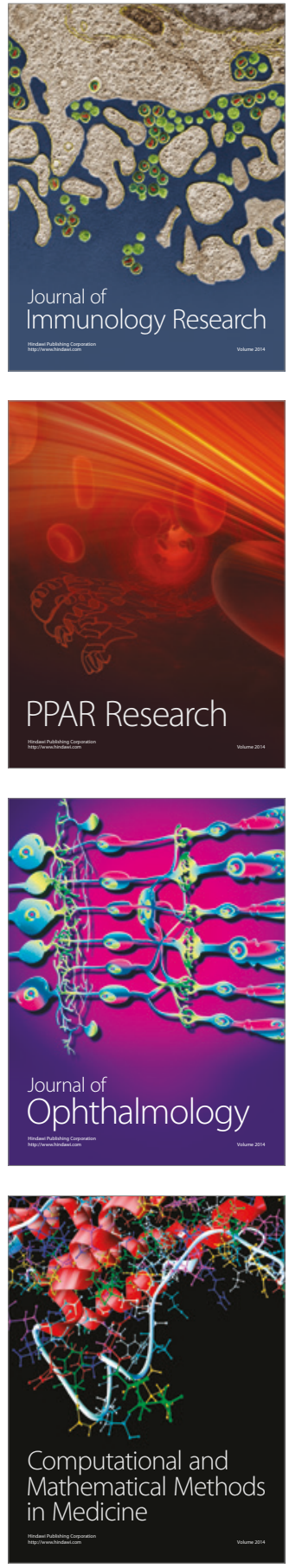

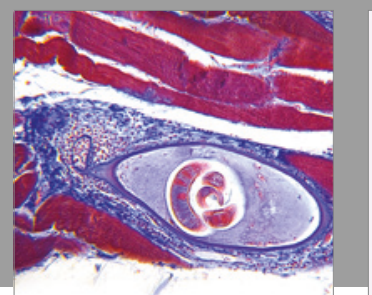

Gastroenterology Research and Practice
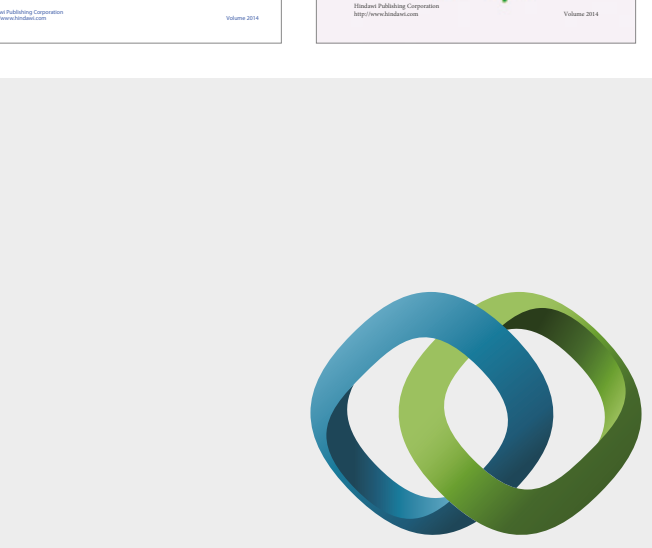

\section{Hindawi}

Submit your manuscripts at

https://www.hindawi.com
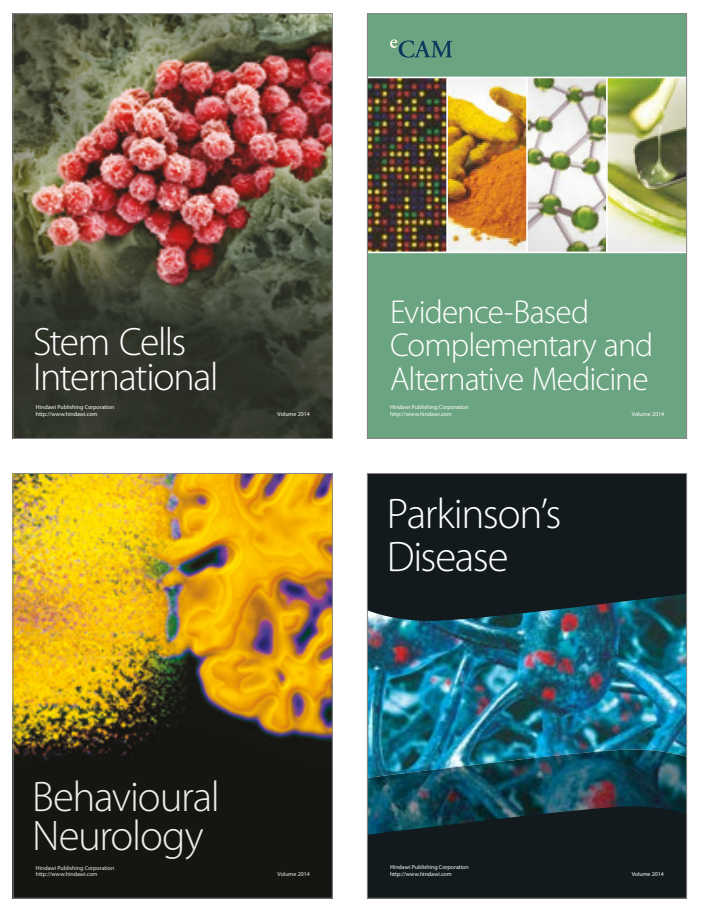
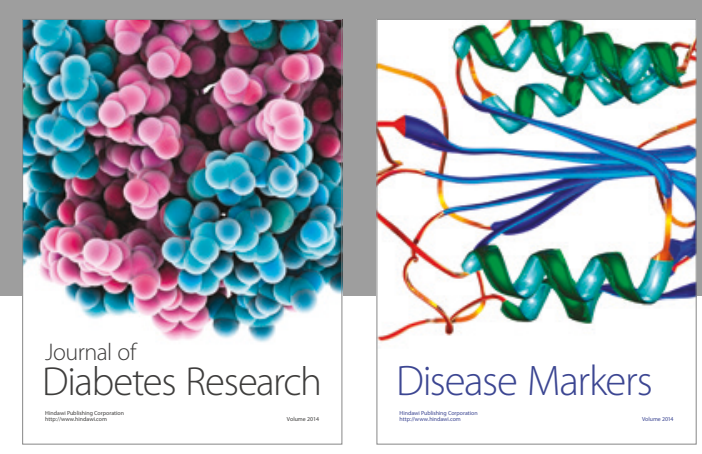

Disease Markers
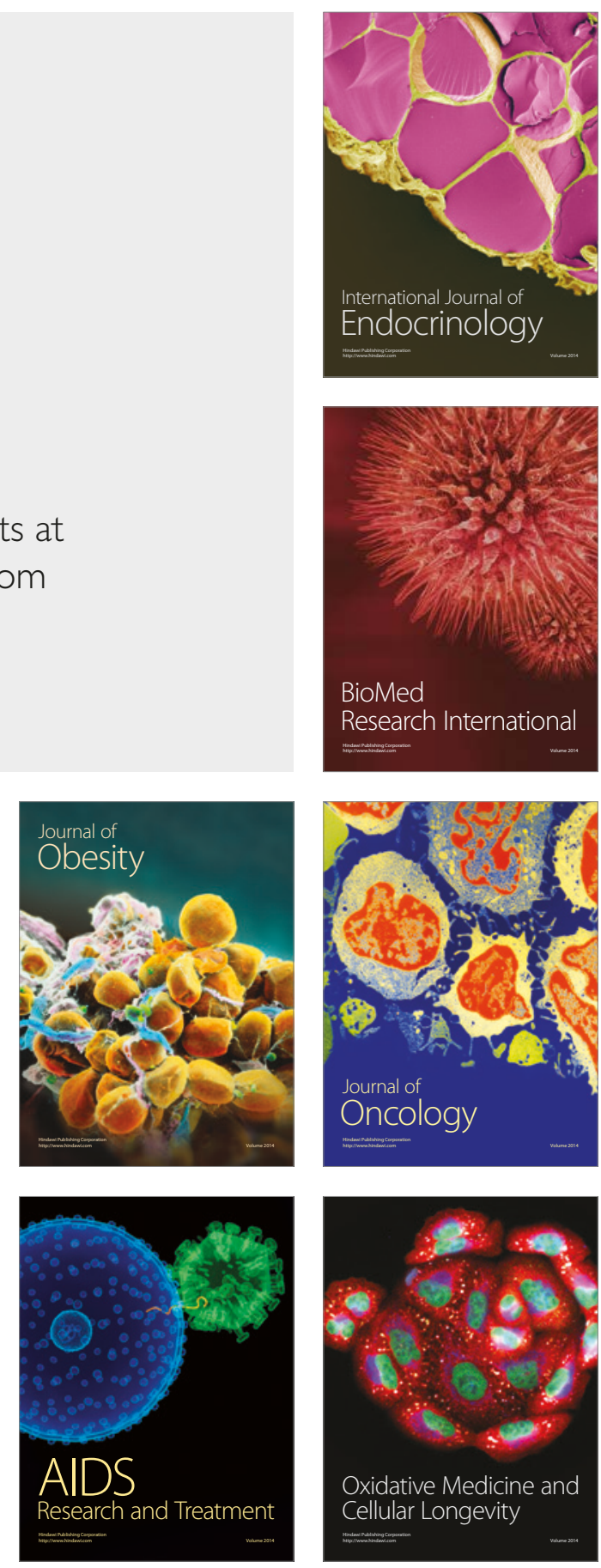